\title{
Thermal decomposition of cobalt(III), nickel(II), copper(II), palladium(II) and platinum(II) complexes of $N$-allyl- $N^{\prime}$-(4'-methylthiazol)-2ylthiourea \\ Naeema H. M. Yarkandi \\ Chemistry Department, Faculty of Applied Science, Umm Al-Qura University, Makkah, Kingdom of Saudi Arabia
}

\begin{abstract}
Thermal decomposition of $\mathrm{Co}(\mathrm{III}), \mathrm{Cu}(\mathrm{II}), \mathrm{Ni}(\mathrm{II}), \mathrm{Pd}(\mathrm{II})$, and $\mathrm{Pt}(\mathrm{II})$ complexes of $N$-allyl- $N^{\prime}-\left(4^{\prime}-\right.$-methylthiazol)-2ylthiourea (AllMeTzTu), HL, have been studied by TG, DTG, and DTA curves. The complexes have the molecular formulae as $\mathrm{CoL}_{3} \cdot \mathrm{H}_{2} \mathrm{O},\left[\mathrm{Cu}(\mathrm{HL}) \mathrm{Cl}_{2}\right] 0.5 \mathrm{H}_{2} \mathrm{O}$ and $\left[\mathrm{CuL}_{2}\left(\mathrm{H}_{2} \mathrm{O}\right)_{2}\right]$ a square for $\mathrm{ML}_{2}\left(\mathrm{M}=\mathrm{Ni}^{\prime \prime}, \mathrm{Pd}^{\prime \prime}\right.$ and $\left.\mathrm{Pt} \mathrm{P}^{\prime \prime}\right)$, and $\left[\mathrm{Pd}(\mathrm{HL}) \mathrm{Cl}_{2}\right]$. The TG curves show that the four-coordinate complexes decompose in two stages to yield a free metal , with exception $\left[\mathrm{Pd}(\mathrm{HL}) \mathrm{Cl}_{2}\right]$ which gives $\mathrm{PdS}$, as a residue, while the two six-coordinate complexes $\mathrm{CoL}_{3} \cdot \mathrm{H}_{2} \mathrm{O}$, and $\left[\mathrm{CuL}_{2}\left(\mathrm{H}_{2} \mathrm{O}\right)_{2}\right]$ decompose in three stages to yield $\mathrm{Co}$ and $\mathrm{Cu}$ residues. The initial mass losses correspond to elimination of allylamine radical for all complexes in the same temperature range; and with MeTz when the temperature range extended beyond that range of the first stage for $\mathrm{Pd}(\mathrm{II})$ and $\mathrm{Pt}(\mathrm{II})$ complexes. Kinetic parameters $\left(E^{\#}, n, \Delta H^{\#}, \Delta S^{\#}, \Delta G^{\#}\right)$ of the decomposition stages are determined and correlated with bonding and structural properties of the complexes.
\end{abstract}

Keywords: Thiazolylthiourea - Transition metal complexes - Thermal decomposition-Thermogravimetry - kinetics

\section{Council for Innovative Research}

Peer Review Research Publishing System

\section{Journal: Journal of Advances in Chemistry}

Vol. 7 , No. 3

editor@cirworld.com

www.cirjac.com, member.cirworld.com 


\section{Introduction}

Thioureas are used as organocatalysts[1], vulcanization accelerators[2], pharmaceuticals[3], plant protection[4], silver polish[5], precipitation of heavy resins[8] electroplating corrosion inhibitors[9], and nylon and textile dyeing. However, increasing claims for probable human carcinogen upon inhalation, ingestion and dermal contact of thioureas or their toxic fumes (nitrogen oxides and sulfur oxides upon thermal decomposition may limit most of their applications in the near future. On the other hand, transition metal ions have proven advantageous in improving thermal stability, modifying thermal decomposition mechanism and products, clarity and the brightness of colour and effectiveness of organic ligands in their applications. The mechanisms of thermal decomposition of some thioureas and their metal complexes have been reported [10,11]. The present paper reports the thermal studies of $\mathrm{Co}(\mathrm{III}), \mathrm{Ni}(\mathrm{II}), \mathrm{Cu}(\mathrm{II}), \mathrm{Pd}(\mathrm{II})$ and $\mathrm{Pt}(\mathrm{II})$ complexes derived from $N$-allyl- $N^{\prime}$-(4'-methylthiazol)-2ylthiourea. The kinetic parameters $n, E$ and $A$ have been determined using Coats-Redfern method [12,13]. The other kinetic parameters $\Delta H^{\#}, \Delta S^{\#}$ and $\Delta G^{\#}$ have been computed using standard equations.

\section{Experimental}

\section{Synthesis of complexes}

The synthesis of the ligand, AllMeTzTu, HL, and corresponding metal complexes are made by the procedures reported earlier [14]. The complexes were prepared from aqueous ethanolic solution of $\mathrm{MCl}_{2}\left(\mathrm{M}=\mathrm{Co}^{\prime \prime}\right.$, $\mathrm{Ni}^{\prime \prime}$ and $\mathrm{Cu}$ ") and AllMeTzTu in mole ratio 1:3 (M:L) for cobalt with aerial oxidation; $1: 2$ for nickel; 1:1 and 1:2 for copper. Palladium(II) and platinum(II) complexes were prepared by reacting aqueous solution of $\left[\mathrm{MCl}_{4}\right]$ with AllMeTzTu dissolved in EtOH in mole ratios 1:1 and $1: 2 ; \mathrm{PtCl}_{2}$ with AllMeTzTu in acetone in mole ratio $1: 2$. The complexes were characterized as a mixture of square planar/tetrahedral for $\mathrm{NiL}_{2}$, as a square planar for $\left[\mathrm{Cu}(\mathrm{HL}) \mathrm{Cl}_{2}\right] 0.5 \mathrm{H}_{2} \mathrm{O},\left[\mathrm{Pd}(\mathrm{AllMeTzTu}) \mathrm{Cl}_{2}\right]$, and $\left[\mathrm{M}(\mathrm{AllMeTzTu})_{2}\right], \mathrm{M}=\mathrm{Pd}(\mathrm{II})$ or $\mathrm{Pt}(\mathrm{II})$ and as an octahedral for $\left[\mathrm{CoL}_{3}\right] \cdot \mathrm{H}_{2} \mathrm{O}$ and $\left[\mathrm{CuL}_{2}\left(\mathrm{H}_{2} \mathrm{O}\right)_{2}\right]$. In all complexes, AllMeTzTu binds metals as a bidentate ligand through thiazole- $\mathrm{N}$ and thiourea-S atoms.

\section{Instrumentation}

The TG, DTG, and DTA curves were obtained using a Shimadzu-50 thermal analyzer. The measurements were performed in dynamic nitrogen atmosphere at a heating rate of $10 \mathrm{C} \mathrm{min}{ }^{-1}$, using approximately 4-6 mg powdered samples contained in a platinum crucible. $\alpha-\mathrm{Al}_{2} \mathrm{O}_{3}$ is used as a reference material.

\section{Results and discussion}

The thermal behavior of AllMeTzTu metal complexes was studied by using TG and DTA techniques from ambient temperature up to $800 \circ \mathrm{C}$ in nitrogen flow, Figs. 1, 2, 3, 4, and 5. The stages of decomposition, temperature ranges, the temperature of the greatest rate of decomposition (DTG $\mathrm{max}_{\text {) }}$, the evolved products, as well as the found and calculated mass loss percentages of $\mathrm{Ni}(\mathrm{II}), \mathrm{Pd}(\mathrm{II})$, and $\mathrm{Pt}(\mathrm{II})$ complexes are given in Table 1.

$\mathrm{NiL}_{2}$

[NiL 2 ] is thermally stable up to $169{ }^{\circ} \mathrm{C}$ and decomposes beyond this temperature in a two stages as indicated in the TG curve, Fig.1. The mass loss at $275^{\circ} \mathrm{C}$ corresponds to the formation of $\mathrm{Ni}(\mathrm{SCN})_{2}[15]$. Beyond $275{ }^{\circ} \mathrm{C}$, a continuous mass loss in the TG curve has been observed up to $575{ }^{\circ} \mathrm{C}$ which corresponds to the decomposition of $\mathrm{Ni}(\mathrm{SCN})_{2}$ to $\mathrm{Ni}$. The DTA profile, Fig. 8 , shows four endothermic peaks at 150, 166, 208 and $389{ }^{\circ} \mathrm{C}$ and one strong exothermic one at $536{ }^{\circ} \mathrm{C}$ The two endothermic peaks at 150 and $166^{\circ} \mathrm{C}$ are in the temperature range of no mass loss on the TG curve and thus correspond to structure change and melting of the complex (M.p. of $\mathrm{NiL}_{2}$ in air $=161^{\circ} \mathrm{C}$ ), respectively. The latter two endothermic peaks at 208 and $389{ }^{\circ} \mathrm{C}$ correspond to the decomposition of $\mathrm{NiL}_{2}$ to $\mathrm{Ni}(\mathrm{SCN})_{2}$ then to $\mathrm{Ni}$, respectively. The strong exothermic peak at $536^{\circ} \mathrm{C}$ is due to dimerization of the evolved and intermediate species[15].

\section{$\mathrm{CoL}_{3} \cdot \mathrm{H}_{2} \mathrm{O}$}

The TG curve, Fig. 2 , shows that the complex begins to decompose beyond $136{ }^{\circ} \mathrm{C}$ in three steps. The first mass loss at $283{ }^{\circ} \mathrm{C}$ corresponds to the formation of $(\mathrm{MeTz})_{3} \mathrm{Co}(\mathrm{SCN})_{3}$. This is followed by two rapid mass losses in the temperature range 283- $566^{\circ} \mathrm{C}$, on the TG curve, collectively assigned to the thermal decomposition of $(\mathrm{MeTz})_{3} \mathrm{Co}(\mathrm{SCN})_{3}$ to $\mathrm{CoS}(\mathrm{SCN})$ which decomposes beyond $715^{\circ} \mathrm{C}$ to CoS. The DTA curve, Fig.8, shows an endothermic peak at $143^{\circ} \mathrm{C}$ corresponds to volatilization of uncoordinated water molecule and melting of the complex (M.p. of the complex in air $=142$ $\left.{ }^{\circ} \mathrm{C}\right)$; an exothermic peak at $248{ }^{\circ} \mathrm{C}$ owing to thermal decomposition of $\mathrm{CoL}_{3}$ to $(\mathrm{MeTz})_{3} \mathrm{Co}(\mathrm{SCN})_{3}$; an endothermic peak at $431^{\circ} \mathrm{C}$ due to decomposition of $(\mathrm{MeTz})_{3} \mathrm{Co}(\mathrm{SCN})_{3}$ to $\mathrm{CoS}(\mathrm{SCN})$; and an exothermic peak at $592{ }^{\circ} \mathrm{C}$ owing to decomposition of $\operatorname{CoS}(\mathrm{SCN})$ to $\mathrm{CoS}$ and dimerization of the evolved radicals[11,15].

\section{$\left[\mathrm{Cu}(\mathrm{HL}) \mathrm{Cl}_{2}\right] \mathbf{0 . 5} \mathrm{H}_{2} \mathrm{O}$}

The TG curve, Fig. ${ }^{*}$, shows an initial mass loss in the temperature range $95-283{ }^{\circ} \mathrm{C}$ corresponding to the decomposition of the complex to $\mathrm{CuCl}(\mathrm{SCN})$. Beyond $283^{\circ} \mathrm{C}$, a continuous mass loss in the TG curve occurs up to $561^{\circ} \mathrm{C}$ which corresponds to the decomposition of $\mathrm{CuCl}(\mathrm{SCN})$ to $\mathrm{Cu}$. The DTA curve, Fig.3, shows an endothermic peak at 233 ' $\mathrm{C}$ owing to thermal decomposition of the complex to $\mathrm{CuCl}(\mathrm{SCN})$ and an exothermic one at $517{ }^{\circ} \mathrm{C}$ owing to decomposition of $\mathrm{CuCl}(\mathrm{SCN})$ to $\mathrm{Cu}$ and dimerization of the evolved radicals. 


\section{$\left[\mathrm{CuL}_{2}\left(\mathrm{H}_{2} \mathrm{O}\right)_{2}\right]$}

The TG curve, Fig.4, indicates that the mass change begins at $138^{\circ} \mathrm{C}$ and continues up to $415^{\circ} \mathrm{C}$. This corresponds to the formation of $\mathrm{Cu}_{2}\left(\mathrm{C}_{2} \mathrm{~N}_{2}\right)_{2}(\mathrm{SCN})_{2}$ as an intermediate product. The next decomposition step occurs in the temperature range $415-673{ }^{\circ} \mathrm{C}$ corresponding to the formation of Cu metal. The DTA curve, Fig.8, shows three endothermic and one exothermic peaks. The first endothermic peak at $201^{\circ} \mathrm{C}$ corresponds to elimination of the two coordinated water molecules and the other two endothermic ones at 226 and $405{ }^{\circ} \mathrm{C}$ are due to melting of $\mathrm{CuL}_{2}\left(\right.$ M.p. of $\left.\left[\mathrm{CuL}_{2}\left(\mathrm{H}_{2} \mathrm{O}\right)_{2}\right]=212^{\circ} \mathrm{C}\right)$ and thermal decomposition of $\mathrm{CuL}_{2}$ to $\mathrm{Cu}_{2}\left(\mathrm{C}_{2} \mathrm{~N}_{2}\right)_{2}(\mathrm{SCN})_{2}$, respectively. The strong exothermic peak at $527{ }^{\circ} \mathrm{C}$ is due to decomposition of $\mathrm{Cu}_{2}\left(\mathrm{C}_{2} \mathrm{~N}_{2}\right)_{2}(\mathrm{SCN})_{2}$ to Cu metal and dimerization of the evolved species.

\section{$\left[\mathrm{Pd}(\mathrm{HL}) \mathrm{Cl}_{2}\right]$}

The TG curve, Fig.5, indicates only one step of decomposition beyond 175 up to $454{ }^{\circ} \mathrm{C}$. This corresponds to formation of PdS which remains stable beyond $454{ }^{\circ} \mathrm{C}$. The DTA curve, Fig.8, show three exothermic peaks at $317,334.7$ and 342454 $\mathrm{C}$ corresponding to decomposition of the complex and dimerization of the evolved radicals.

\section{$\mathrm{PdL}_{2}$}

The TG curve, Fig.6, shows that the mass loss begins at $195^{\circ} \mathrm{C}$ in two steps. The mass loss at $283^{\circ} \mathrm{C}$ corresponds to the elimination of two allylamide and methyl radicals with the formation of an unstable intermediate formulated as $(\mathrm{TzSCN})_{2} \mathrm{Pd}$ which is immediately decomposes in the temperature range $283-516{ }^{\circ} \mathrm{C}$ to $\mathrm{Pd}$ metal. The DTA curve, Fig. 8 , shows two endothermic and one exothermic peak. The exothermic peaks at 211 and $231{ }^{\circ} \mathrm{C}$ correspond to melting (M.p. of $\mathrm{PdL}_{2}$ in air $=210{ }^{\circ} \mathrm{C}$ ) and thermal decomposition of $\mathrm{PdL}_{2}$ to the unstable intermediate, respectively ; and the exothermic peak at $480{ }^{\circ} \mathrm{C}$ is owing to the decomposition of the intermediate complex to $\mathrm{Pd}$ metal and dimerization of the free radicals.

\section{$\mathrm{PtL}_{2}$}

The complex is thermally stable up to $215^{\circ} \mathrm{C}$, as indicated by the TG curve, Fig. 7 , but beyond this temperature it decomposes in three steps. The first decomposition step is in the temperature range $215-250{ }^{\circ} \mathrm{C}$ which corresponds to the elimination of two allylamide and one methyl radicals with the formation of an unstable intermediate complex which decomposes in two successive steps (Table 1) eliminating TzSCN and MeTzCN radicals with the formation of Pt metal at $610^{\circ} \mathrm{C}$. The DTA curve, Fig.8, shows two endothermic at 182 and $198{ }^{\circ} \mathrm{C}$ with no weight loss in the TG curve, owing to crystal change and melting (M.p. in air $=195^{\circ} \mathrm{C}$ ) points of the complex; and one strong broad exothermic peak extended from $216^{\circ} \mathrm{C}$ to $270{ }^{\circ} \mathrm{C}$ with a maximum at $234^{\circ} \mathrm{C}$ corresponding to the first decomposition step of the original complex and combination of the free radicals. Also, exothermic small peaks could be traced beyond this range due to thermal decomposition of the two successive steps.

In order to assess the influences of the mode of bonding of the ligand to the metal ions and the structural properties of the complexes on their thermal behavior, the order, $n$, and the heat of activation $E^{\#}$ of the various decomposition stages were determined from the TG and DTG thermograms using the Coats-Redfern equations $[12,13]$ in the following form:

$\begin{array}{ll}\ln \left[\frac{(1-\alpha)^{1-n}}{(1-n) T^{2}}\right]=\frac{M}{T}+B & \text { for } n \neq 1 \\ \ln \left[\frac{-\ln (1-\alpha)}{T^{2}}\right]=\frac{M}{T}+B & \text { for } n=1\end{array}$

Where $M=-E^{\#} / R$ and $B=\ln A R / \Phi E^{\#} ; E^{\#}, R, A$, and $\Phi$ are the heat of activation, universal gas constant, pre-exponential factor, and heating rate, respectively. The correlation coefficient, $r$, was computed using the least squares methods for different values of $n$, by plotting the left-hand side of the Eqs. 1 and 2 versus 1000/T. The $n$ value which gave the best fit $(r \approx 1)$ was chosen as the order parameter for the decomposition stage of interest. From the intercept and linear slope of such stage, the $A$ and $E^{\#}$ values were determined. The other kinetic parameters, $\Delta H^{\#}, \Delta S^{\#}$ and $\Delta G^{\#}$ were computed using the relationships: $\quad \Delta H^{\#}=E^{\#}-R T, \Delta S^{\#}=R[\ln (A h / k T)-1]$ and $\Delta G^{\#}=\Delta H^{\#}-T \Delta S^{\#}$, where $k$ is the Boltzmann's constant and $h$ is the Planck's constant. The kinetic parameters are collected in Table 2. The fol lowing remarks can be pointed out:

(i) The positive values of the activation entropies $\Delta S^{\#}$ indicate a less ordered activated complex than the reactants and the reactions are rapid [16].

(ii) There is no obvious trends in the values of the heat of activation $E^{\#}$, the activation enthalpies $\Delta H^{\#}$ or $\Delta G^{\#}$. However, the similar values of $\Delta G^{\#}$ of the first step of all complexes are comparable, revealing that activation of this step is governed by the decomposing $\mathrm{HN}-\mathrm{CH}_{2}-\mathrm{CH}=\mathrm{CH}_{2}$ species.

(iii) Though $\Delta H^{\#}$ values of the final decomposition step which involves the coordination core for structurally related compounds $\mathrm{ML}_{2}\left(\Delta H^{\#}=157.83 \mathrm{kJmol}^{-1}\right.$ for $\mathrm{NiL}_{2} ; \Delta H^{\#}=133.77 \mathrm{kJmol}^{-1}$ for $\mathrm{PdL}_{2} ; \Delta H^{\#}=104.83 \mathrm{kJmol}^{\prime}$

${ }_{1}^{1}$ for $\left.\mathrm{PtL}_{2}\right)$ obey the metal ion radius rule. However, the similar $\Delta G^{\#}$ values of this final step of $\mathrm{ML}_{2}\left(\Delta G^{\#}=\right.$ $77.08 \mathrm{kJmol}^{-1}$ for $\mathrm{NiL}_{2} ; \Delta G^{\#}=72.10 \mathrm{kJmol}^{-1} ; \Delta G^{\#}=73.65 \mathrm{kJmol}^{-1}$ for $\mathrm{PtL}_{2}$ ), suggest that the entropy term 
,$T \Delta S^{\#}$, overrides the $\Delta H^{\#}$ values and thus, the effect of the ligands is more pronouncd than that of the divalent metals. This could be justified by the high $\Delta H^{\#}$ value of the final step for decomposition of the trivalent cobalt complex, $\left[\mathrm{CoL}_{3}\right] \cdot \mathrm{H}_{2} \mathrm{O}\left(\Delta H^{\#}=384.65 \mathrm{kJmol}^{-1}\right)$, and the relatively low value of $\Delta G^{\#}$ for the decomposition $\left(\Delta G^{\#}=91.07 \mathrm{kJmol}^{-1}\right)$.

(iv) The $\Delta H^{\#}$ value of the first decomposition step of the octahedral $\left[\mathrm{CuL}_{2}\left(\mathrm{H}_{2} \mathrm{O}\right)_{2}\right]\left(\Delta H^{\#}=105.16 \mathrm{kJmol}^{-1}\right)$ is higher than the corresponding step of all divalent complexes. This could be explained in terms of crystal field stabilization energy, since this step involves decomposition of coordinated species to copper ion, as $\mathrm{H}_{2} \mathrm{O}$ and MeTz.

(v) Though, $\Delta H^{\#}$ values of the final step for octahedral complexes [ $\left.\mathrm{CoL}_{3}\right] \cdot \mathrm{H}_{2} \mathrm{O}$ and $\left[\mathrm{CuL}_{2}\left(\mathrm{H}_{2} \mathrm{O}\right)_{2}\right]$ are significantly different and consistent with charge -to radius ratio. However, the small difference of $\Delta G^{\#}$ values for the two complexes could be attributed to the structural rigidity of the remaining cobalt(III) complex versus structural flexibility of copper(II) compound at this stage of decomposition, as revealed by the low $\Delta S^{\#}$ value for copper(II) species $\left(\Delta S^{\#}=16.8 \mathrm{Jmol}^{-1}\right)$ and the high $\Delta S^{\#}$ value for cobalt(III) species $\left(\Delta S^{\#}=285.6 \mathrm{Jmol}^{-1}\right)$.

(vi) The reaction orders for all decomposition stages of all complexes are found to be nearly equal unity. It was emphasized that the order of a solid-state decomposition reaction has no intrinsic meaning, but is rather a mathematical smoothing parameter [17].

\section{References}

1. Zhang Z, Schreiner PR. Thiourea-catalyzed transfer hydrogenation of aldimines. Synlett 2007; 9:1455-1457.

2. Reshmy R, Thomas KK., Sulekha A.N-benzoyl-N'N'-disubstituted thiourea- A new binary accelerator system and its effect of nucleophilicity in vulcanization of natural rubber. J Appl Poly Sci. 2012;124(2): 978-984.

3. Englert H, Mania D, Hartung J, Gögelein H, Kaiser J, Linz J, Wettlaufer D. Substituted benzenesulfoylurea and thioureas-process for their preparation and their use as pharmaceuticals.US Patent 5574069, 1996.

4. Enders E, Stendel W, Hammann I. $N$-aryl- $N^{\prime}$-(cyclo)-alkyl-thioureas and their use as agents for combating animal pests and plant pests. US Patent 4194008, 1980.

5. Laing M, Beeston M. Silver polish formulation containing thiourea. US Patent 5958854, 1999.

6. Schuster M., Koeing K., Lotter H., Drauz K. Substituted thioureas for separation of complexly bound heavy-metal ions. US Patent 4980071, 1990.

7. Tokyo I, Asami T. Thermographic diazo-type copying paper. US Patent 3615574, 1971.

8. Katritzky AR, Cai X, Rogovoy BV. Solid state synthesis and application of trisustituted thioureas. J Comb Chem. 2003; 5(4):392-399.

9. Donepudi VS, Venkatachalapathy R, Ozemoyah PO. Electrodepsition of copper from sulfate electrolytes: Effects of thiourea on resistivity and electrodeposition mechanism of copper. Electrochem Solid-State Lett. 2001;4(2):C13-C16.

10. Lizarraga E, Zabaleta C, Palop JA. Mechanism of thermal decom- position of thiourea derivatives. J Therm Anal Calorim. 2008; 93 887-98.

11. Katib SMA. Thermal decomposition of nickel(II), palladium(II) and platinum(II) complexes of N-allyl-N'-pyrimidin2ylthiourea. J Therm Anal Calorim. 2011;103(2):647-652.

12. Coats AW, Redfern JP. Kinetic parameters from thermogravimetric data. Nature. 1964;201:68-9.

13. Kandil SS, El-Hefnawy GB, Baker EA. Thermal and spectral studies of 5-(phenylazo)-2-thiohydantoin and 5-(2hydroxyphenylazo)-2- thiohydantoin complexes of cobalt(II), nickel(II) and copper(II). Thermochim Acta. 2004; 414:105-113.

14. a) Jambi SMS, Yarkandy NHM, Kandil SS. Synthesis and spectroscopic characterization of Pt(II), $\mathrm{Pd}(\mathrm{II}), \mathrm{Ni}(\mathrm{II}), \mathrm{Co}$ (III) and $\mathrm{Cu}(\mathrm{II})$ complexes of N-allyl-N'-(4-methylthiazol)-2ylthiourea. press

b) Kandil SS, Katib SMA, Yarkandi NHM.Nickel(II), palladium(II) and platinum(II) complexes of N-allyl-N'-pyrimid 2ylthiourea. 2007;32:791-798.

15. Özpozan N, Arslan H, Özpozan T, Özdes N, Külcü N. Thermal studies of Ni(II), Pt(II) and Ru(III) complexes of N, Ndihexyl- N'-benzoylthiourea. Thermochim Acta. 2000;343:127-33.

16. Forst AA, Pearson RG. Kinetics and mechanisms. New York: Wiley; 1961.

17. Brown DB, Walton EG, Dits JA. Thermal reactions of the mixed valence iron flourides, $\mathrm{Fe}_{2} \mathrm{~F}_{6} . \mathrm{nH}_{2} \mathrm{O}$. J Chem Soc Dalton Trans. 1980;845-50. 